\title{
U-shaped relationship of age at diagnosis and cancer-specific mortality in primary urachal adenocarcinoma: a cohort study
}

\author{
Dong-Dong $\mathrm{Yu}^{1}$, Hui Dong ${ }^{2}$, Zhi-Gang $\mathrm{Wu}^{1}$, Yun-Bei Xiao ${ }^{1}$, Chao-Feng Zhou ${ }^{1}$, Qin-Quan Wang ${ }^{1}$, \\ Jian Cai ${ }^{1}$
}

${ }^{1}$ Department of Urology, ${ }^{2}$ Department of Respiratory Medicine, The First Affiliated Hospital of Wenzhou Medical University, Whenzhou, China Contributions: (I) Conception and design: DD Yu, J Cai, QQ Wang, CF Zhou; (II) Administrative support: J Cai; (III) Provision of study materials or patients: All authors; (IV) Collection and assembly of data: DD Yu, H Dong; (V) Data analysis and interpretation: All authors; (VI) Manuscript writing: All authors; (VII) Final approval of manuscript: All authors.

Correspondence to: Prof. Dr. Jian Cai; Dr. Qin-Quan Wang; Dr. Chao-Feng Zhou. Department of Urology, The First Affiliated Hospital of Wenzhou Medical University, NO.2, Fuxue Road Lucheng District, Whenzhou, China. Email: cjhospital@yeah.net; 1962354417@qq.com; zcfnba2008@163.com.

Background: To examine the association between age at diagnosis and cancer-specific mortality (CSM) in primary urachal adenocarcinoma.

Methods: The data was obtained from the National Cancer Institute's Surveillance, Epidemiology, and End Results program (SEER). A total of 393 patients were included in the study. Smooth curve fitting and two-piecewise Cox proportional hazards models were used to identify the nonlinearity between the age at initial diagnosis and cancer-specific survival rate. Survival time between different groups was compared using Kaplan-Meier survival curves and the log-rank test.

Results: Using smooth curve fitting we found that the relationship between age at diagnosis and cancerspecific survival takes on a U-shaped curve. The inflection point that we identified for the age at initial diagnosis was 60 years. The log-likelihood ratio test $(\mathrm{P}<0.05)$ indicated that the two-piecewise Cox regression model was more appropriate for fitting the correlation of age at diagnosis and CSM. The two-piecewise Cox regression model showed that when the age was $<60$ years, reduced risk of CSM was significantly associated with increased age (HR: 0.95, $\mathrm{P}=0.0002)$. Conversely, when age was $>60$ years, increased risk of CSM was significantly associated with increased age (HR: 1.05, $\mathrm{P}=0.0499)$.

Conclusions: In summary, our study suggested that the relationship between age at diagnosis and cancerspecific survival is nonlinear, and takes on a U-shaped curve. Both younger and older age at initial diagnosis age were associated with increased CSM.

Keywords: U-shaped curve, Primary Urachal Adenocarcinoma, cancer-specific mortality, surveillance epidemiology and end results

Submitted Dec 13, 2019. Accepted for publication May 19, 2020.

doi: $10.21037 /$ tau-19-863

View this article at: http://dx.doi.org/10.21037/tau-19-863

\section{Introduction}

Bladder cancer is the most common cancer of the urinary system, with urothelial carcinoma constituting greater than $90 \%$ of pathological types. Urachal cancer is a rare form of tumor associated with a high degree of malignancy, late staging and poor prognosis, accounting for approximately
$0.2-0.5 \%$ of all malignant tumors of the bladder (1-3). Adenocarcinoma is the most common histological subtype of urachal carcinoma $(4,5)$. Primary urachal adenocarcinoma has been rarely studied due to its low incidence. Case series provide most of the available evidence in the medical literature. It has previously been observed that several disease-specific factors (e.g., stage of the disease $(1,5-7)$, 
histologic subtype (6), presence of positive margins after surgery $(8,9)$, pathological tumor grade $(5,10)$, presence of positive lymph nodes and type of surgery (8) were closely related to the prognosis.

Age is known to be an important predictor in many tumors (11-14). However, the influence of age at diagnosis on outcomes in patients with primary urachal adenocarcinoma remains unclear. Ashley et al. analyzed the 50 years data from Mayo Clinic and concluded that older age was associated with malignant cell in a urachal mass (8). Wright et al. evaluated 151 patients in the National Cancer Institute's Surveillance, Epidemiology, and End Results program (SEER) database and demonstrated that age was not an independent prognostic factor in urachal adenocarcinoma (6).

Understanding the association of age at diagnosis and outcomes may not only have prognostic implications but may also have important therapeutic significances for the development of molecular targeted cancer therapy and personalized medicine (13). In our study, we evaluated data from a large, nationwide, population-based database to investigate the effect of age at initial diagnosis on cancer-specific mortality (CSM) of primary urachal adenocarcinoma patients. We present the following article in accordance with the STROBE reporting checklist (available at http://dx.doi.org/10.21037/tau-19-863).

\section{Methods}

We used a retrospective cohort study design. The data was obtained from the National Cancer Institute's SEER program, which includes approximately $28 \%$ of the U.S. population. We used the International Statistical Classifications of Diseases for Oncology, 3rd edition (ICD-O-3) site codes C677 and histology codes 8140-8147 and $8255-8490$ to identify primary urachal adenocarcinoma. Additional inclusion criteria were as follows: (I) urachal adenocarcinoma that was the first malignancy; (II) patients for whom information about CSM, duration of survival (in months), and therapy provided were available; and (III) diagnosis was by histological confirmation only. Cases diagnosed by clinical presentation, radiography, or autopsy alone were excluded.

\section{Ethical statement}

We were granted permission from the National Cancer
Institute USA to access the SEER dataset for research purposes only (reference number: 18015-Nov2017). All the data from the SEER database were de-identified, and the extracted data did not require informed consent.

\section{Statistical analysis}

Continuous variables such as age are presented as median and interquartile range median (IQR). Categorical variables such as race are presented as counts and percentages. Twosample $t$-test was used for continuous variable analysis, and chi-square test was used for continuous variable analysis. Univariate Cox regression analysis was performed to identify potential risk factors. After factors were identified, we explored the nonlinear relationship between age at diagnosis and cancer-specific survival using a smoothing plot. Using a trial method, the inflection point of age at diagnosis at which the relationship began to change was identified. The trial inflection point was moved along a predetermined interval to detect the inflection point to obtain the maximum model likelihood $(15,16)$. Survival time between the different groups was compared using Kaplan-Meier survival curves. The X-tile software was used to identify the best cutoff value in the Kaplan-Meier curves. Then we used multivariate Cox regression model and a two-piecewise Cox regression model to explore the relationship of age at diagnosis on cancer-specific survival according to the smoothing plot. The log-rank test was used to compare the two curves. Data were analyzed using the statistical package $\mathrm{R}$ (the $\mathrm{R}$ foundation; http://www. r-project.org; version3.4.3) and EmpowerStats software (www.empowerstats.com, $\mathrm{X} \& \mathrm{Y}$ solutions, Inc. Boston MA).

\section{Results}

\section{Demographic Characteristics}

A total of 393 patients were included in the analysis according to the criteria described above (Figure 1). The demographic and clinicopathological characteristics of study patients are presented in Table 1. The median age was 45 years (range, 19 to 91 years), The majority of the patients were White (303 patients, $77.10 \%), 216$ (54.96\%) were male and 250 (63.61\%) were married. The median followup time was 41 months (range, 0 to 394 months), and 205 $(52.16 \%)$ patients died before the last follow-up, of which 155 (39.44\%) patients died due to primary adenocarcinomas of the urachus. 


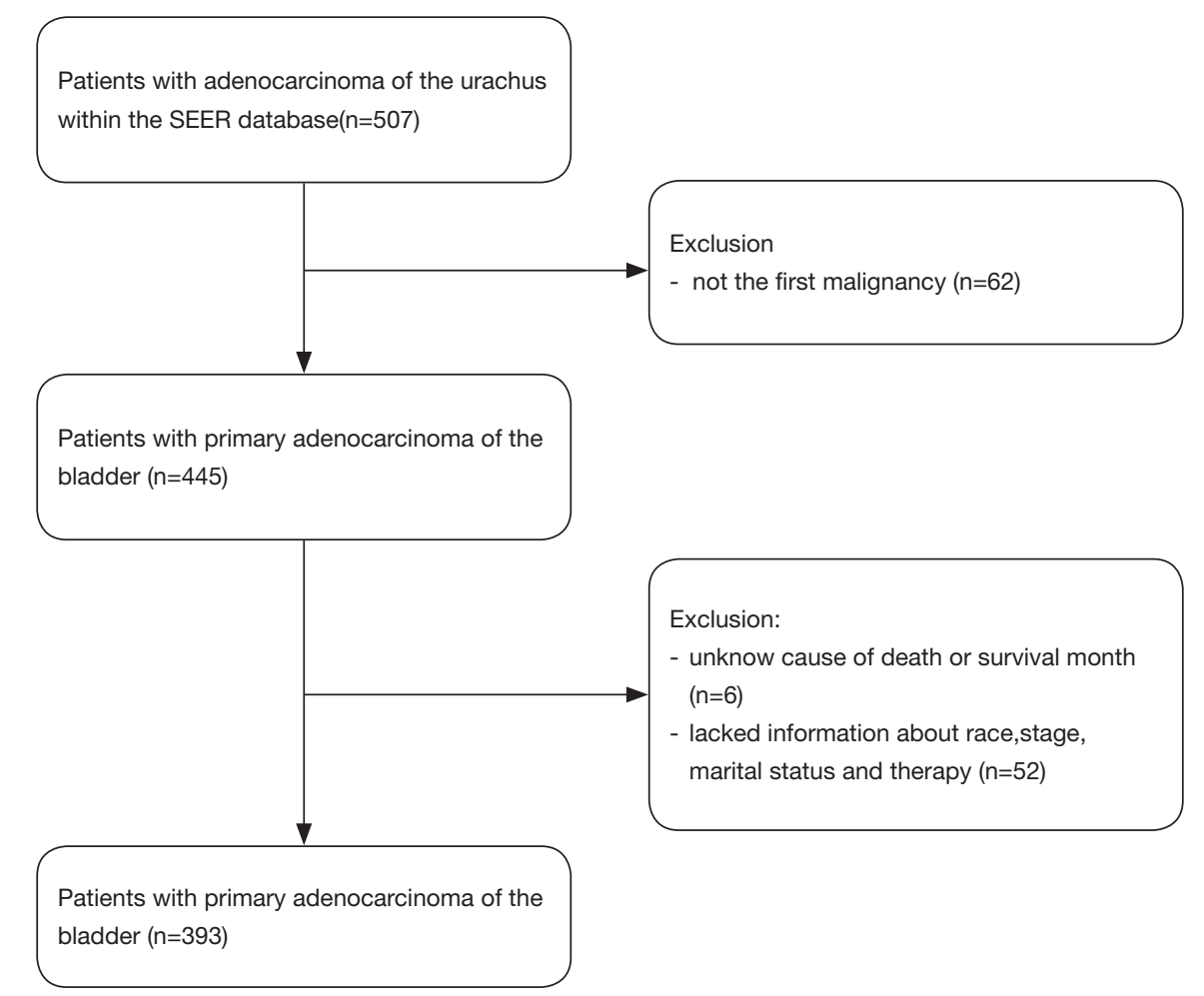

Figure 1 Flow chart of participant selection.

\section{Pathologic and clinical characteristics}

Considering the tumor the stage and grade, a majority of patients $(210,57.07 \%)$ had tumors that were staged as regional and the tumors of $137(47.90 \%)$ patients were graded as moderately differentiated (Grade II). Staging data was missing in $25(6.36 \%)$ patients and our analysis showed that these data met the "missing at random" hypothesis. In general, 361 (91.86\%) patients underwent cancer-directed surgery. Among them, 46 (11.70\%) patients had transurethral resection, 250 (63.61\%) had partial cystectomy, and 45 (11.45\%) had cystectomy. A small number of patients received chemotherapy $(106,26.97 \%)$ or radiation treatment $(42,10.69 \%)$.

\section{Correlation between age at diagnosis and cancer specific death}

Univariate Cox regression analysis was performed to identify potential risk factors associated with CSM, as shown in Table 2. Patients with Signet ring cell adenocarcinoma (HR: 2.03, $\mathrm{P}=0.0213$ ), poorly differentiated cells (HR: 3.44, $\mathrm{P}=0.0002$ ), regional stage (HR: 2.16, $\mathrm{P}=0.0226$ ), distant stage (HR: 8.34, $\mathrm{P}<0.0001$ ), have received radiotherapy (HR: 2.29, $\mathrm{P}=0.0001$ ), had received chemotherapy (HR: 2.13, $\mathrm{P}<0.0001)$ were associated with worse prognosis. Patients who had undergone surgery (HR: $0.26, \mathrm{P}<0.0001$ for transurethral resection; HR: $0.14, \mathrm{P}<0.0001$ for partial cystectomy; HR: $0.23, \mathrm{P}<0.0001$ for cystectomy; HR: $0.23, \mathrm{P}=0.0001$ for other surgical methods), had a better prognosis than those who were not surgical patients.

\section{The independent correlation between age at diagnosis and cancer-specific survival rate}

After possible confounders were identified using univariate Cox regression analysis, smooth curve fitting was performed after adjusting all variables. The curve showed a twostage change and one inflection point (Figure 2), meaning that there was an inverse association between age at initial diagnosis and cancer-specific survival when age was before the inflection point, and there was a positive relationship between age and cancer specific survival rate when age was after the inflection point. The inflection point that we identified for age at initial diagnosis was 60 years. KaplanMeier analyses showed that in patients $<60$ years of age, 
Table 1 Clinical characteristics of the 393 patients with primary adenocarcinoma of the urachus

\begin{tabular}{|c|c|c|c|c|}
\hline Variable & $<60(n=231)$ & $\geq 60(n=162)$ & Total $(n=393)$ & P-value \\
\hline Sex, n (\%) & & & & 0.8310 \\
\hline Male & $128(55.41)$ & 88 (54.32) & $216(54.96)$ & \\
\hline Female & 103 (44.59) & $74(45.68)$ & $177(45.04)$ & \\
\hline Race, n (\%) & & & & 0.1900 \\
\hline Black & $28(12.12)$ & $11(6.79)$ & $39(9.92)$ & \\
\hline Other & $31(13.42)$ & $20(12.35)$ & $51(21.98)$ & \\
\hline Grade, n (\%) & & & & 0.4600 \\
\hline Well differentiated; Grade I & $27(15.88)$ & $24(20.69)$ & $51(17.83)$ & \\
\hline Histologic type, n (\%) & & & & 0.3740 \\
\hline Adenocarcinoma NOS & $87(37.66)$ & $72(44.44)$ & $159(40.64)$ & \\
\hline Mucinous adenocarcinoma & $126(54.55)$ & $74(45.68)$ & $200(50.89)$ & \\
\hline Signet ring cell adenocarcinoma & $11(4.76)$ & $9(5.56)$ & $20(5.09)$ & \\
\hline Other adenocarcinoma subtypes & $7(3.03)$ & $7(4.32)$ & $14(3.56)$ & \\
\hline SEER historic stage $\mathrm{A}, \mathrm{n}(\%)$ & & & & 0.2100 \\
\hline Localized & $27(12.16)$ & $26(17.81)$ & $53(14.40)$ & \\
\hline Regional & $136(61.26)$ & $74(50.68)$ & $210(57.07)$ & \\
\hline Distant & $56(25.23)$ & $43(29.45)$ & $99(26.90)$ & \\
\hline Yes & $66(28.57)$ & $40(24.69)$ & $106(26.97)$ & \\
\hline None/unknown & $165(71.43)$ & $122(75.31)$ & $287(73.03)$ & \\
\hline Surgery, n (\%) & & & & 0.5050 \\
\hline No cancer-direct surgery & $16(6.93)$ & $16(9.88)$ & $32(8.14)$ & \\
\hline Transurethral resection & $26(11.26)$ & $20(12.35)$ & $46(11.7)$ & \\
\hline Partial cystectomy & $152(65.80)$ & $98(60.49)$ & $250(63.61)$ & \\
\hline Cystectomy & $28(12.12)$ & $17(10.49)$ & $45(11.45)$ & \\
\hline Other surgery type & $9(3.90)$ & $11(6.79)$ & $20(5.09)$ & \\
\hline Marital status at diagnosis, $\mathrm{n}(\%)$ & & & & $<0.001^{\star \star *}$ \\
\hline Married & $148(64.07)$ & $102(62.96)$ & $250(63.61)$ & \\
\hline Never married & $62(26.84)$ & $20(12.35)$ & $82(20.87)$ & \\
\hline Other $^{\mathrm{a}}$ & $21(9.09)$ & $40(24.69)$ & $61(15.52)$ & \\
\hline
\end{tabular}

Statistically significant ${ }^{*} \mathrm{P}<0.05,{ }^{* \star} \mathrm{P}<0.01,{ }^{* * *} \mathrm{P}<0.001$. IQR, interquartile range; Localized, confined entirely to the organ of origin; Regional, has extended 1) beyond the limits of the organ of origin directly into surrounding organs or tissues; 2) into regional lymph nodes by way of the lymphatic system; or 3) by a combination of extension and regional lymph nodes; Distant, has spread to parts of the body remote from the primary tumor either by direct extension or by discontinuous metastasis; Unstaged, unknow stage. ${ }^{a}$ Other includes divorced, separated, widowed and unmarried or domestic partner. 
Table 2 Univariate Cox regression analysis of prognostic factors for cancer-specific mortality in primary urachal adenocarcinoma

\begin{tabular}{|c|c|c|c|c|}
\hline Variable & Level & $\mathrm{HR}$ & $95 \% \mathrm{Cl}$ & $P$ value \\
\hline Age at diagnosis (years) median (IQR), year & $56(45-65)$ & 1.00 & $(0.99-1.01)$ & 0.6497 \\
\hline \multicolumn{5}{|l|}{ Sex, n (\%) } \\
\hline Male & $216(54.96)$ & 0.99 & $(0.72-1.36)$ & 0.9483 \\
\hline \multicolumn{5}{|l|}{ Race, n (\%) } \\
\hline Black & $39(9.92)$ & 1.29 & $(0.79-2.13)$ & 0.3087 \\
\hline Other & $51(12.98)$ & 1.49 & $(0.96-2.31)$ & 0.0786 \\
\hline \multicolumn{5}{|l|}{ Grade, n (\%) } \\
\hline Well differentiated; Grade I & $51(17.83)$ & Reference & & \\
\hline Moderately differentiated; Grade II & $137(47.90)$ & 1.42 & $(0.73-2.78)$ & 0.3019 \\
\hline \multicolumn{5}{|l|}{ Histologic type, n (\%) } \\
\hline Adenocarcinoma NOS & $159(40.46)$ & Reference & & \\
\hline Mucinous adenocarcinoma & $200(50.89)$ & 1.05 & $(0.74-1.47)$ & 0.7927 \\
\hline Signet ring cell adenocarcinoma & $20(5.09)$ & 2.03 & $(1.11-3.72)$ & $0.0213^{*}$ \\
\hline Other adenocarcinoma subtypes & $14(3.56)$ & 0.99 & $(0.40-2.48)$ & 0.9877 \\
\hline \multicolumn{5}{|l|}{ SEER historic stage A, n (\%) } \\
\hline Localized & $53(14.40)$ & Reference & & \\
\hline Regional & $210(57.07)$ & 2.16 & $(1.11-4.20)$ & $0.0226^{*}$ \\
\hline Distant & $99(26.90)$ & 8.34 & $(4.28-16.27)$ & $<0.0001^{\star * \star}$ \\
\hline Yes & $106(26.97)$ & 2.13 & $(1.53-2.95)$ & $<0.0001^{\star \star \star}$ \\
\hline \multicolumn{5}{|l|}{ Surgery, n (\%) } \\
\hline No cancer-direct surgery & $32(8.14)$ & Reference & & \\
\hline Transurethral resection & $46(11.70)$ & 0.26 & $(0.15-0.46)$ & $<0.0001^{\star \star \star}$ \\
\hline Partial cystectomy & $250(63.61)$ & 0.14 & $(0.09-0.22)$ & $<0.0001^{\text {*** }}$ \\
\hline Cystectomy & $45(11.45)$ & 0.23 & $(0.13-0.41)$ & $<0.0001^{\star \star \star}$ \\
\hline Other surgery type & $20(5.09)$ & 0.23 & $(0.11-0.49)$ & $<0.0001^{\star * \star}$ \\
\hline \multicolumn{5}{|l|}{ Marital status, n (\%) } \\
\hline Married & $250(63.61)$ & Reference & & \\
\hline Never married & $82(20.87)$ & 1.12 & $(0.75-1.67)$ & 0.5722 \\
\hline Other $^{\mathrm{a}}$ & $61(15.52)$ & 1.40 & $(0.91-2.15)$ & 0.1219 \\
\hline
\end{tabular}

Statistically significant ${ }^{*} \mathrm{P}<0.05,{ }^{* \star} \mathrm{P}<0.01,{ }^{* *} \mathrm{P}<0.001 . \mathrm{Cl}$, confidence interval; HR, hazard ratio. ${ }^{\mathrm{a}}$ Other includes divorced, separated, widowed and unmarried or domestic partner. 


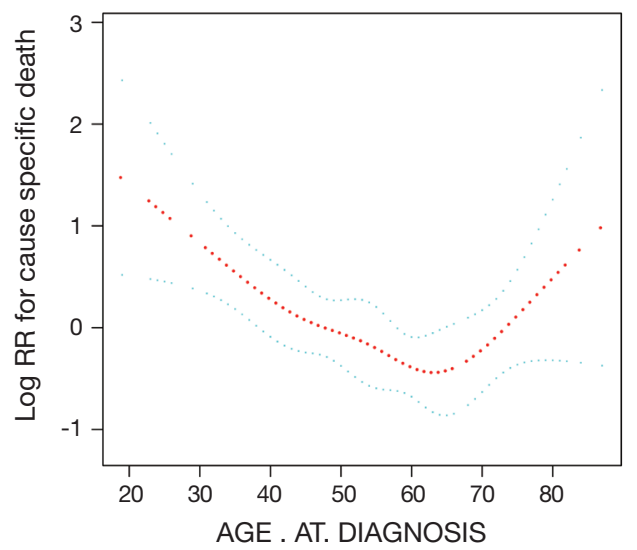

Figure 2 The relationship between age at diagnosis and cancerspecific mortality. A nonlinear relationship was observed after adjusting for race, sex; histologic type, grade, stage, radiation, chemotherapy, marital status, surgery, year of diagnosis.

worse prognosis was associated with younger age $(\mathrm{P}=0.0007$; Figure $3 A$ ). In patients $\geq 60$ years of age, worse prognosis was associated with older age $(\mathrm{P}=0.0025$; Figure $3 B)$. These results confirm the association identified by smooth curve fitting. Then we used a Cox regression model and a twopiecewise Cox regression model to fit the association between age at diagnosis and CSM, respectively. The $\log$ likelihood ratio test $(\mathrm{P}<0.05)$ indicated that the twopiecewise Cox regression model was more appropriate for fitting the correlation of age at diagnosis and CSM, as shown in Table 3. The two-piecewise Cox regression model showed that when the age was $<60$ years, reduced risk of CSM was significantly associated with increased age (HR: $0.95, \mathrm{P}=0.0002$ ). Conversely, when age was $\geq 60$ years, increased risk of CSM was significantly associated with increased age (HR: 1.05, $\mathrm{P}=0.0499)$.

\section{Discussion}

The urachus is a remnant of the allantois and forms the medial umbilical ligament after birth. Urachal carcinoma occurs mostly in the patent urachal duct (17). Urachal cancer is a rare malignant tumor, first described by Begg in 1930 (18), representing less than $1 \%$ of bladder cancers. The median diagnosis age is 52 years which is earlier than that of non-urachal adenocarcinoma $(8,10,19)$.

Patients with urachal adenocarcinoma are more likely to be male and have the mucinous subtype. In this study, most patients were male $(216,54.96 \%)$ and had the mucinous adenocarcinoma subtype (200,50.89\%). These results are similar to those reported by Szarvas et al. 2016 (19). Previous studies have shown that compared with patients with non-urachal tumors, those with primary urachal adenocarcinoma had a higher risk of suffering from nonorgan-confined disease (6). In this study, 309 (78.63\%) patients had a regional or distant stage. This may be due to the intramural growth of the adenocarcinoma leading to late onset hematuria, urinary tract irritation and other symptoms, and thus, a late stage of diagnosis (20). What is surprising is that when compared with patients with nonurachal adenocarcinoma of the bladder, individuals with urachal adenocarcinoma still had a better survival outcome. The reported five-year survival rates were $48 \%$ and $35 \%$ for patients with urachal and non-urachal adenocarcinoma, respectively $(4,6)$.

Several staging approaches have been proposed for urachal cancer (e.g., the Sheldon system and the alternative Mayo, Ontario, and TNM systems). However, no staging system has been verified $(7,8,10)$. In this study, we used the SEER historic stage A (localized, regional, distant and unstaged) classification system because it is the only staging system that was used continuously throughout the study period from 1973-2015. Several studies have shown that the presence of an advanced stage is associated with a poor prognosis $(1,6,7)$.

At present, the main treatment of urachal adenocarcinoma is radical surgery (21). However, there is no significant survival advantage between complete cystectomy and partial cystectomy $(20,22)$. Adenocarcinoma is not sensitive to radiotherapy or chemotherapy $(23,24)$. Szarvas et al. (19) and Tatli et al. (23) believed that chemotherapy regimens containing 5-FU can improve the prognosis in patients with adenocarcinoma of the bladder, while others have indicated that radiotherapy, neo-adjuvant chemotherapy, or adjuvant chemotherapy have not proven to be efficacious in treatment of adenocarcinoma of the bladder (21,25-27).

In this study we found that the relationship between age at diagnosis and mortality is nonlinear and takes on a U-shaped curve. Both younger and older ages at initial diagnosis were associated with increased CSM. The risk of cancer-specific death in older patients ( $\geq 60$ years) was markedly increased, which may be expected considering the possibility of less healthy patients, decreased overall life expectancy, and inability to tolerate invasive surgery or other regimens. Survival outcomes are not necessarily improved in younger patients, although they are generally 

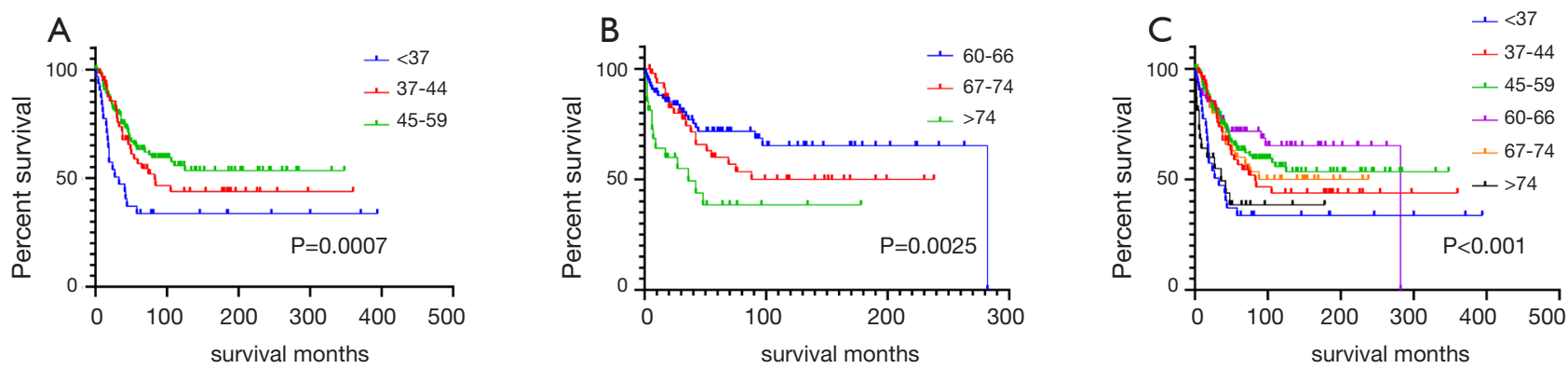

Figure 3 Kaplan-Meier curves of cancer-specific mortality in patients $<60$ years old (A); $\geq 60$ years old (B); in the entire cohort (C).

Table 3 Threshold effect analysis of age at diagnosis on cancer-specific mortality using two-piecewise Cox regression

\begin{tabular}{lccc}
\hline Inflection point of age at diagnosis & Odds ratio & $95 \% \mathrm{Cl}$ & $\mathrm{P}$ value \\
\hline$<60$ & 0.95 & $(0.93-0.98)$ & $0.0002^{\star \star \star}$ \\
$\geq 60$ & 1.05 & $(1.00-1.10)$ & $0.0499^{\star}$ \\
Log-rank test & & $0.004^{\star \star}$ & \\
\hline
\end{tabular}

Statistically significant ${ }^{\star} \mathrm{P}<0.05,{ }^{\star \star} \mathrm{P}<0.01$, ${ }^{\star \star \star} \mathrm{P}<0.001$. Cl, confidence interval; HR, hazard ratio. Two-piecewise Cox regression hazards models were also adjusted for race; sex; histologic type; grade; stage; radiation; chemotherapy; marital status; surgery; year of diagnosis.

healthier and have fewer comorbidities than older patients, which may reflect differing biology. This finding is contrary to results of previous studies in which age at diagnosis was not an independent covariate associated with CSM in patients with primary urachal adenocarcinoma (6). A possible explanation for this might be that the non-linear association is difficult to identify using a single-piecewise cox regression model. In the era of molecular targeted cancer therapy and personalized medicine, our finding may have both important prognostic and therapeutic implications (28).

We should admit that there are some limitations in our research. First, our research was retrospective, which is inevitably associated with selection bias. Second, the distinction between urachal and non-urachal primary adenocarcinoma has always been a challenge problem in clinically and pathology (29-31). Therefore, there is a potential misclassification bias. Considering this situation, we performed an additional analysis after excluding the primary site of dome lesions; however, there was no significant change in our result (not shown in the article). Third, the SEER database lacks information about treatment strategies, family history, occupation, tumor markers, biochemical factors and immunological factors, which may cause bias. However, this is a real-world study based on a large sample, and these limitations do not weaken our conclusions.

In summary, our study suggested that the relationship between age at diagnosis and cancer-specific survival is nonlinear and takes on a U-shaped curve. Both younger and older ages at initial diagnosis were associated with increased CSM. Further studies are needed to evaluate the actual role of age at diagnosis in CSM as well as the underlying biological mechanism.

\section{Acknowledgments}

The authors are grateful to all the staff at the National Cancer Institute (USA) for their contribution to the SEER program.

Funding: None.

\section{Footnote}

Reporting Checklist: The authors have completed the STROBE reporting checklist. Available at http://dx.doi. org/10.21037/tau-19-863

Conflict of Interest: All authors have completed the ICMJE uniform disclosure form (available at http://dx.doi. org/10.21037/tau-19-863). The authors have no conflicts of interest to declare. 
Ethical Statement: The authors are accountable for all aspects of the work in ensuring that questions related to the accuracy or integrity of any part of the work are appropriately investigated and resolved. We were granted permission from the National Cancer Institute USA to access the SEER dataset for research purposes only (reference number: 18015-Nov2017). All the data from the SEER database were de-identified, and the extracted data did not require informed consent.

Open Access Statement: This is an Open Access article distributed in accordance with the Creative Commons Attribution-NonCommercial-NoDerivs 4.0 International License (CC BY-NC-ND 4.0), which permits the noncommercial replication and distribution of the article with the strict proviso that no changes or edits are made and the original work is properly cited (including links to both the formal publication through the relevant DOI and the license). See: https://creativecommons.org/licenses/by-nc-nd/4.0/.

\section{References}

1. Bruins HM, Visser O, Ploeg M, et al. The Clinical Epidemiology of Urachal Carcinoma: Results of a Large, Population Based Study. J Urol 2012;188:1102-7.

2. Sheldon CA, Clayman RV, Gonzalez R, et al. Malignant urachal lesions. J Urol 1984;131:1-8.

3. Hamilou Z, North S, Canil C, et al. Management of urachal cancer: A review by the Canadian Urological Association and Genitourinary Medical Oncologists of Canada. Can Urol Assoc J 2020;14:E57-64.

4. Natale C, Leinwand GZ, Chiang J, et al. Reviewing the Demographic, Prognostic, and Treatment Factors of Primary Adenocarcinoma of the Bladder: A SEER Population-based Study. Clin Genitourin Cancer 2019;17:380-8.

5. Mylonas KS, P OM, Ziogas IA, et al. Malignant urachal neoplasms: A population-based study and systematic review of literature. Urol Oncol 2017;35:33.e11-33.e19.

6. Wright JL, Porter MP, Li CI, et al. Differences in survival among patients with urachal and nonurachal adenocarcinomas of the bladder. Cancer 2006;107:721-8.

7. Molina JR, Quevedo JF, Furth AF, et al. Predictors of survival from urachal cancer: a Mayo Clinic study of 49 cases. Cancer 2007;110:2434-40.

8. Ashley RA, Inman BA, Sebo TJ, et al. Urachal carcinoma: clinicopathologic features and long-term outcomes of an aggressive malignancy. Cancer 2006;107:712-20.
9. Niedworok C, Panitz M, Szarvas T, et al. Urachal Carcinoma of the Bladder: Impact of Clinical and Immunohistochemical Parameters on Prognosis. J Urol 2016;195:1690-6.

10. Pinthus JH, Haddad R, Trachtenberg J, et al. Population Based Survival Data on Urachal Tumors. J Urol 2006;175:2042-7.

11. Zhang J, Gan L, Xu MD, et al. The prognostic value of age in non-metastatic gastric cancer after gastrectomy: a retrospective study in the U.S. and China. J Cancer 2018;9:1188-99.

12. Cavanaugh-Hussey MW, Mu EW, Kang S, et al. Older Age is Associated with a Higher Incidence of Melanoma Death but a Lower Incidence of Sentinel Lymph Node Metastasis in the SEER Databases (2003-2011). Ann Surg Oncol 2015;22:2120-6.

13. Humphreys MR, Fernandes KA, Sridhar SS. Impact of Age at Diagnosis on Outcomes in Men with Castrate-Resistant Prostate Cancer (CRPC). J Cancer 2013;4:304-14.

14. Azim HA, Jr., Nguyen B, Brohee S, et al. Genomic aberrations in young and elderly breast cancer patients. BMC Med 2015;13:266.

15. Liu S, Wang X, Lu Y, et al. The effects of intraoperative cryoprecipitate transfusion on acute renal failure following orthotropic liver transplantation. Hepatol Int 2013;7:901-9.

16. Hu L, Hu G, Xu BP, et al. U-Shaped Association of Serum Uric Acid with All-cause and Cause-Specific Mortality in US Adults: A Cohort Study. J Clin Endocrinol Metab 2020;105:dgz068.

17. Peugniez C, Ghoneim T, Leroy X, et al. Urachal cancers. Bull Cancer 2013;100:509-17.

18. Begg RC. The Urachus: its Anatomy, Histology and Development. J Anat 1930;64:170-83.

19. Szarvas T, Modos O, Niedworok C, et al. Clinical, prognostic, and therapeutic aspects of urachal carcinoma-A comprehensive review with meta-analysis of 1,010 cases. Urol Oncol 2016;34:388-98.

20. Henly DR, Farrow GM, Zincke H. Urachal cancer: role of conservative surgery. Urology 1993;42:635-9.

21. Tsironis G, Bamias A. Treating bladder adenocarcinoma. Transl Androl Urol 2018;7:S699-701.

22. Siefker-Radtke A. Urachal Adenocarcinoma: A Clinician's Guide for Treatment. Semin Oncol 2012;39:619-24.

23. Tatli AM, Uysal M, Goksu SS, et al. Complete response of primary bladder adenocarcinoma with the FOLFOX4 regimen. Urol Int 2015;94:363-5. 
24. Davaro F, Schaefer J, May A, et al. Invasive non-urachal adenocarcinoma of the bladder: analysis of the National Cancer Database. World J Urol 2019;37:497-505.

25. Porten SP, Willis D, Kamat AM. Variant histology: role in management and prognosis of nonmuscle invasive bladder cancer. Curr Opin Urol 2014;24:517-23.

26. Alanee S, Alvarado-Cabrero I, Murugan P, et al. Update of the International Consultation on Urological Diseases on bladder cancer 2018: non-urothelial cancers of the urinary bladder. World J Urol 2019;37:107-14.

27. Spiess PE, Agarwal N, Bangs R, et al. Bladder Cancer, Version 2.2017, NCCN Clinical Practice Guidelines in

Cite this article as: Yu DD, Dong $\mathrm{H}, \mathrm{Wu} \mathrm{ZG}$, Xiao YB, Zhou CF, Wang QQ, Cai J. U-shaped relationship of age at diagnosis and cancer-specific mortality in primary urachal adenocarcinoma: a cohort study. Transl Androl Urol 2020;9(3):1073-1081. doi:10.21037/tau-19-863
Oncology. J Natl Compr Canc Netw 2017;15:1240-67.

28. Nyirady P, Niedworok C, Reis H, et al. Clinical Sequencing-guided Therapy of Urachal Carcinoma: New Perspective for a Rare Cancer. Eur Urol 2016;70:776-7.

29. Gopalan A, Sharp DS, Fine SW, et al. Urachal carcinoma: a clinicopathologic analysis of 24 cases with outcome correlation. Am J Surg Pathol 2009;33:659-68.

30. Johnson DE, Hodge GB, Abdul-Karim FW, et al. Urachal carcinoma. Urology 1985;26:218-21.

31. Maslov DV, Thomas K, Matrana M. Chemotherapy Toxicity Confirms Diagnosis of Urachal Carcinoma. Clin Genitourin Cancer 2019;17:e913-5. 